\title{
LA CONCILIACIÓN DE LA VIDA LABORAL Y FAMILIAR EN ARGENTINA A PARTIR DE LA EXPERIENCIA ESPAÑOLA: HACIA UNA POLÍTICA PÚBLICA BASADA EN LA CORRESPONSABILIDAD Y SOLIDARIDAD FAMILIAR
}

\author{
Luis H. Olaguibe \\ Doctor en Derecho, Universidad Católica de Santa Fe, \\ Santa Fe, Argentina \\ Contacto: lolaguibe@ucsf.edu.ar \\ ORCID: https://orcid.org/0000-0002-9536-6384

\section{José Olaguibe} \\ Máster en Gobierno y Cultura de las Organizaciones, \\ Universidad de Navarra, Pamplona, España \\ Contacto: jiolaguibe@gmail.com \\ ORCID: https://orcid.org/0000-0003-4464-6260
}

Recibido: 31 de agosto de 2020

Aprobado: 12 de octubre de 2020

Para citar este artículo:

Olaguibe, L. H. y Olaguibe, J. (2021). "La conciliación de la vida laboral y familiar en Argentina a partir de la experiencia española: Hacia una política pública basada en la corresponsabilidad y solidaridad familiar". Prudentia Iuris, N. 91, pp. 101-126 DOI: https://doi.org/10.46553/prudentia.91.2021.pp.101-126 
Resumen: La conciliación de la vida laboral y familiar constituye un reto que afecta a varones y mujeres y representa una cuestión social que incide en el empleo, pero también impacta al conjunto de la sociedad. La evolución de las políticas legislativas tendientes a facilitar la armonía de la vida laboral y familiar en España y las transformaciones sociales de las últimas décadas ponen en evidencia la necesidad de actualizar el ordenamiento jurídico argentino. Este artículo pretende revisar las políticas públicas en Argentina con una mirada integradora y desde una perspectiva de corresponsabilidad y solidaridad familiar. Con esa premisa se resaltan los principios constitucionales de igualdad de oportunidades y libertad de decisión, en sintonía con la protección de la institución familiar para avanzar hacia una efectiva política pública en materia de conciliación.

Palabras clave: Conciliación trabajo-familia, Corresponsabilidad, Solidaridad familiar, Política pública. 


\title{
The Conciliation of Work and Family Life in Argentina from the Spanish Experience: Towards a Public Policy Based on Co-Responsibility and Family Solidarity
}

\begin{abstract}
The conciliation of work and family life is a challenge that affects men and women and represents a social issue that has an impact on employment, but also on society as a whole. The evolution of legislative policies designed to facilitate the balance between work and family life in Spain and the social transformations of the last few decades highlight the need to update the Argentinean legal system. This article aims to review public policies in Argentina with an integrative view and from a perspective of coresponsibility and family solidarity. Under this premise, the constitutional principles of equal opportunities and freedom of decision are highlighted, in line with the protection of the family institution, in order to advance towards an effective public policy in the field of conciliation.
\end{abstract}

Keywords: Work-family conciliation, Co-responsibility, Family solidarity, Public policy.

\section{La conciliazione della vita professionale e familiare in Argentina sulla base dell'esperienza spagnola: Verso una politica pubblica basata sulla corresponsabilità e sulla solidarietà familiare}

Sommario: Conciliare lavoro e vita familiare è una sfida che riguarda sia gli uomini che le donne e rappresenta una questione sociale che ha un impatto sull'occupazione, ma anche sulla società nel suo complesso. L'evoluzione delle politiche legislative volte a facilitare l'armonia della vita lavorativa e familiare in Spagna e le trasformazioni sociali degli ultimi decenni dimostrano la necessità di aggiornare il sistema giuridico argentino. Questo articolo si propone di rivedere le politiche pubbliche in Argentina con una visione integrativa e da una prospettiva di corresponsabilità e di solidarietà familiare. Con questa premessa, i principi costituzionali delle pari opportunità e della libertà di decisione sono messi in evidenza in armonia con la tu- 
tela dell'istituzione familiare, al fine di progredire verso un'efficace politica pubblica in materia di riconciliazione.

Parole chiave: Conciliazione lavoro-famiglia, Co-responsabilità, Solidarietà familiare, Politiche pubbliche.

\section{Introducción}

La conciliación de la vida laboral y familiar se presenta como una de las tensiones más importantes de la sociedad contemporánea. Constituye un reto que afecta a varones y mujeres, y representa una cuestión social que incide en el empleo pero que también impacta irremediablemente en el conjunto de la sociedad. Entre sus consecuencias resaltan las dificultades que ocasiona en la realidad de muchas parejas para tener hijos y trabajar ${ }^{1}$, lo que repercute significativamente en los bajos índices de fecundidad de los países occidentales, principalmente la región de Europa del $\mathrm{sur}^{2}$, y en las últimas décadas también se reflejan en los países latinoamericanos ${ }^{3}$.

Si bien los procesos en cada continente se desarrollan asimétricamente desde un punto de vista temporal, creemos que los efectos y el modo de abordar los problemas pueden enriquecerse si se tienen en cuenta ambas experiencias. Por eso, a partir de un estudio de la evolución de la legislación española y argentina se pretende reflexionar acerca de cómo se encuentran las políticas públicas en Argentina, hacia dónde deberían tender y de qué manera se pueden integrar a la normativa vigente. En este sentido, este trabajo tiene como fin brindar aportes significativos en materia legislativa que permitan avanzar hacia una efectiva política pública de conciliación en sintonía con los principios constitucionales de igualdad de oportunidades y libertad de decisión y la protección de la institución familiar.

En primer lugar, se describe el problema de integrar el desarrollo profesional a la vida personal y familiar que hoy afecta a varones y mujeres, tanto en Europa como en América Latina. La relevancia de la temática se funda en las consecuencias intrafamiliares y sociales que ocasiona el he-

1 Cfr. Olmo Vicén, N.; Montoro Gurich, C. y López, D. (2011). "El reto de tener hijos y trabajar: Un análisis desde la socio-demografía”. En Montoro Gurich, C. (Ed.), Familias con dos sueldos y tres trabajos. Pamplona. Instituto de Ciencias para la Familia, Servicio de Publicaciones de la Universidad de Navarra, 86-113.

2 Van De Kaa, D. J. (1997). “Options and sequences: Europe's demographic patterns". Journal of the Australian Population Association, 14 (1), 1-30.

3 Cfr. CEPAL. (2020). Observatorio Demográfico, 2019. Santiago de Chile. 
cho de no disponer de mecanismos o herramientas pertinentes para lograr una armonía de las distintas esferas: personal, familiar y laboral. Entre las primeras se destacan dificultades para trabajar y tener hijos ${ }^{4}$, como así también para brindar una buena educación a los niños acorde al ciclo vital en que se encuentren y, por ende, para el cuidado de los mismos cuando sea necesario. Las consecuencias sociales se aprecian en los cambios demográficos de las últimas décadas, con efectos claros en la disminución de la fecundidad y en la postergación de la maternidad y paternidad ${ }^{5}$. Lo que hace imprescindible atender la necesidad de debatir sobre cómo la sociedad del siglo XXI hace frente a estas dificultades, en particular, las que se presentan a la hora de armonizar el trabajo y la vida personal y familiar; y desde la política pública, cómo facilitar estos aspectos que forman parte del proyecto vital de la mayoría de los ciudadanos.

A continuación, se realiza una revisión bibliográfica-legislativa de las políticas públicas implementadas en España y Argentina. Se observan, en ambos casos, medidas concretas con relación a los permisos por maternidad y paternidad, el cuidado y las responsabilidades de padres y madres. Para el caso argentino, se pretende plantear un marco jurídico más amplio que excede la legislación laboral y contempla principios constitucionales, tratados internacionales y otras leyes de fondo. Vale aclarar que, si bien los tratados resultan aplicables a todos los países que los han ratificado, metodológicamente serán presentados en el apartado destinado al análisis del caso argentino en razón de haber recibido jerarquía constitucional por el artículo 75 , inciso 22 de la Constitución Nacional. Por último, a modo de retos legislativos, se busca brindar algunos aportes que, ante la ausencia de políticas públicas en Argentina tendientes a facilitar la integración de la vida laboral y familiar, se consideran oportunos y necesarios. Entre ellos, los principios de corresponsabilidad y solidaridad familiar como criterios rectores para el diseño de políticas de conciliación.

\section{La armonía entre el trabajo y la vida personal y familiar en el siglo XXI}

El nuevo rol de la mujer en la sociedad ha sido de los hechos más relevantes del siglo pasado. Este fenómeno trajo consigo un nuevo modo de comprender las responsabilidades familiares, mayores oportunidades de

4 Cfr. Olmo Vicén, N.; Montoro Gurich, C. y López, D., ob. cit.

5 Cfr. Sánchez Barricarte, J. (2008). El crecimiento de la población mundial. Implicaciones socioeconómicas, ecológicas y éticas. Valencia. Tirant Lo Blanch. 
formación profesional para las mujeres y una modificación en las trayectorias vitales femeninas ${ }^{6}$. Esto significó un cambio en la forma de vida de las familias, dado que antes la mujer se encargaba de las tareas del hogar y el varón del trabajo fuera de él, ahora la mujer tiene mayor autonomía económica y laboral ${ }^{7}$.

Por otra parte, la concepción del trabajo ha cambiado: tanto para varones como para mujeres, ya no es solo un medio de subsistencia para el grupo familiar, sino que responde más al concepto de carrera profesional y constituye una de las principales motivaciones de las personas y de las nuevas generaciones; de hecho, tanto el empleo como el tipo de ocupación forman parte de la construcción de la propia identidad ${ }^{8}$. Esto también ha tenido consecuencias en el proyecto personal y familiar de los ciudadanos que en muchas ocasiones deben postergar tener el primer hijo por razones económicas y/o por dificultades para conciliar la vida laboral y familiar ${ }^{9}$. El impacto se aprecia a nivel micro, es decir, en la misma unidad familiar; pero también a nivel macro, lo que ocasiona serios problemas de índole demográficos que, tal vez, en el corto plazo no se logran identificar, pero que a mediano y largo plazo tienen serias consecuencias ${ }^{10}$.

La familia en cuanto realidad humana natural transita tiempos históricos transformadores, que no deben diluir su verdadero significado de comunidad de personas unidas por vínculos afectivos y jurídicos. Esa idea de comunidad aplicada al matrimonio contiene dos elementos fundacionales, como son la solidaridad y la participación en la construcción de ese proyecto personal y familiar ${ }^{11}$. Hacer factible la armonía entre la vida laboral y la vida familiar requiere de una adecuada distribución del tiempo, recursos y esfuerzos a lo largo del tiempo. Sin embargo, conseguir un desarrollo integral que incluya estos aspectos no es tarea fácil; es necesario un replanteo del modo de vivir los diferentes roles que cada persona ejerce en el ámbito familiar y laboral, sin caer en un ordenamiento matemático igualitario ${ }^{12}$.

6 Cfr. Esping-Andersen, G. y Palier, B. (2010). Los tres grandes retos del Estado del bienestar. Barcelona. Editorial Ariel.

7 Cfr. López, D. (2016). "El reto de la conciliación trabajo y familia: ¿qué nos estamos jugando?". En Familia y sociedad en el siglo XXI. Madrid. Dykinson, 27-38.

8 Goldin, C. (2006). “The Quiet Revolution That Transformed Women's Employment, Education, and Family". En AEA Papers and Proceedings, 1-21. Madrid.

9 Cfr. INE (2019a). Nota de prensa: Encuesta de Fecundidad 2018. Datos definitivos.

10 Cfr. Livi Bacci, M. (2012). Historia mínima de la población mundial. $4^{\mathrm{a}}$ ed. Barcelona. Editorial Ariel.

11 Cfr. Hervada, J. (2000). Una caro. Escritos sobre el matrimonio. Pamplona. EUNSA, 575.

12 Cfr. Ordoñez y Revuelta, M. (2016). Familia + Trabajo: Un camino hacia la integración. Buenos Aires. Lid Editorial. 
Además, es necesario comprender que el trabajo y la familia son parte de una misma vida, y si bien son ámbitos diferentes resulta clave que ambos no entren en conflicto, sino que se integren ${ }^{13}$.

En España, a modo de ejemplo, según la Encuesta de Fecundidad de 2018 que realiza el Instituto Nacional de Estadística (INE), tres de cada cuatro mujeres desean tener al menos dos hijos, pero la realidad muestra que el número medio de hijos es menor ${ }^{14}$. La brecha que revela esta encuesta entre el número de hijos que se desean tener y los hijos que se tienen se observa tanto en las mujeres como en los varones. Entre las razones que aducen las mujeres por las que han tenido menos hijos de los deseados resaltan las dificultades para conciliar la vida laboral y familiar como las más relevantes. Asimismo, revisten importancia las razones económicas y de salud. En el caso de los varones también manifiestan el factor de la conciliación, aunque en primer lugar mencionan las razones económicas como barrera para tener los hijos que desean.

Por tanto, en este contexto las políticas públicas destinadas a facilitar la conciliación de la vida laboral y familiar de los ciudadanos revisten mayor importancia y forman parte de las respuestas que los gobiernos, en el marco del diálogo social y la amplia participación ciudadana, ofrecen a la población ${ }^{15}$. A partir de las diversas experiencias, fundamentalmente de los países del norte de Europa, pioneros en políticas de conciliación, en la actualidad se estima que la corresponsabilidad entre varones y mujeres es el factor más influyente para facilitar la conciliación. Además, es un mecanismo para fomentar una mayor dedicación temporal al cuidado y la atención de los hijos que redunda en mayor bienestar para ellos y para el propio padre o madre, así como para promover un reparto de las responsabilidades laborales y familiares entre los miembros de la familia en función de su realidad particular ${ }^{16}$.

Las políticas públicas de los países europeos están siendo orientadas en este sentido, como es el caso de España. Mientras que en los países latinoamericanos, como es el caso de Argentina, aún esto no ha sido materia de suficiente debate, si bien existen algunos proyectos de ley presentados y algunos recientemente sancionados que se encuadran en el interés público de facilitar y fomentar la conciliación laboral y familiar a través de algunas

13 Cfr. Chinchilla, N. y Moragas, M. (2007). Dueños de nuestro destino. Cómo conciliar la vida profesional, familiar y personal. Barcelona. Ariel.

14 Cfr. INE (2019b). España en cifras 2019. Madrid.

15 OIT-PNUD (2009). Trabajo y Familia: Hacia nuevas formas de conciliación con corresponsabilidad social. Santiago de Chile, 13.

16 Meil Landwerlin, G. (2017). "Permisos parentales para hombres y corresponsabilidad en el cuidado de niños”. Revista del Ministerio de Empleo y Seguridad Social, 131, 15-34. 
acciones concretas. Un ejemplo de esto es la sanción de la Ley $N^{o} 27.555$ que regula el teletrabajo en todo el territorio argentino, donde en el artículo $6^{\circ}$ se reconoce a quienes acrediten tener a su cargo, de manera única o compartida, el cuidado de personas menores de trece (13) años, personas con discapacidad o adultas mayores que convivan con la persona trabajadora y que requieran asistencia específica, el derecho a horarios compatibles con las tareas de cuidado a su cargo y/o a interrumpir la jornada ${ }^{17}$. Sin ánimo de discutir el contenido de toda la normativa que busca regular esta modalidad laboral, se destaca un cambio en la perspectiva de las tareas referidas al cuidado de los más vulnerables en la familia, ya no determinada a un sexo, sino puesta a consideración de la libertad de los miembros de la pareja.

Los organismos internacionales, por su parte, también insisten en la promoción de la corresponsabilidad como clave para la conciliación. La Organización de las Naciones Unidas (ONU), a través de la Organización Internacional del Trabajo (OIT), sostiene desde hace tiempo la necesidad de avanzar hacia la conciliación de la esfera laboral y familiar con corresponsabilidad social, es decir, entre varones y mujeres, así como también entre familias, estado, mercado y sociedad en general ${ }^{18}$. Se considera la corresponsabilidad como una dimensión fundamental para promover la igualdad y combatir la pobreza desde el mundo del trabajo, y un requisito para lograr la equidad entre varones y mujeres.

Ciertamente, la sociedad poco a poco tiende a una mayor igualdad entre varones y mujeres en la vida social, en el mercado de trabajo y en el reparto de las responsabilidades familiares. El acceso de la mujer al mundo laboral, la mayor participación de los varones en el hogar, el creciente deseo del desarrollo profesional tanto en mujeres como varones, entre otros cambios sociales, han significado un gran avance como sociedad. Pero también, han puesto en evidencia la necesidad de repensar la legislación en materia de empleo y de seguridad social, de desarrollar y aplicar nuevas políticas tanto en lo privado como en lo público.

17 Artículo $6^{\circ}$ de la Ley $\mathrm{N}^{\circ}$ 27.555. "Tareas de cuidados. Las personas que trabajen bajo esta modalidad y que acrediten tener a su cargo, de manera única o compartida, el cuidado de personas menores de trece (13) años, personas con discapacidad o adultas mayores que convivan con la persona trabajadora y que requieran asistencia específica, tendrán derecho a horarios compatibles con las tareas de cuidado a su cargo y/o a interrumpir la jornada. Cualquier acto, conducta, decisión, represalia u obstaculización proveniente del empleador que lesione estos derechos se presumirá discriminatorio resultando aplicables las previsiones de la Ley $\mathrm{N}^{\circ}$ 23.592. Mediante la negociación colectiva podrán establecerse pautas específicas para el ejercicio de este derecho".

18 OIT-PNUD, ob. cit., 11. 


\section{Evolución de las políticas legislativas de conciliación del trabajo y la vida personal y familiar en España}

\section{III.a. Primera etapa: Ley $N^{o} 39 / 1999$, de 5 de noviembre, de conciliación de la vida familiar y laboral de las personas trabajadoras en España}

La primera Ley de conciliación de la vida familiar y laboral de las personas trabajadoras en España (Ley $\mathrm{N}^{\circ} 39 / 1999$, de 5 de noviembre) se dicta durante el año 1999. En la exposición de motivos se recogen como fundamentos constitucionales de todo el cuerpo normativo: 1) el artículo 14 de la Constitución española, donde explícitamente se postula el derecho a la igualdad ante la ley y el principio de no discriminación por razón de nacimiento, raza, sexo, religión u opinión o cualquier otra condición; 2) el artículo 39.1, donde se establece el deber de los poderes públicos de asegurar la protección social, económica y jurídica de la familia; y 3) el artículo 9.2 , que atribuye a los poderes públicos el deber de promover las condiciones para que la libertad y la igualdad del individuo y de los grupos en que se integran sean reales y efectivas; y de remover los obstáculos que impidan o dificulten su plenitud facilitando la participación de todos los ciudadanos en la vida política, económica, cultural y social.

Se reconoce, así, la necesidad de acompañar uno de los cambios más profundos de este siglo, que es la incorporación de la mujer al trabajo. De esta forma, el Estado español, en línea a las recomendaciones internacionales, reconoce la necesidad de abordar las nuevas relaciones sociales y un nuevo modo de cooperación y compromiso entre mujeres y varones que facilite un reparto equilibrado de responsabilidades en la vida profesional, personal y familiar.

Esta normativa tiene como principal aspiración conseguir una mayor igualdad entre varones y mujeres, a través de favorecer la conciliación de la vida laboral y familiar; siendo el trabajo y la familia los ámbitos de mayor incidencia. El Estado de España, de esta manera, define los aspectos formales que marcarán el rumbo de las futuras políticas públicas de conciliación en concordancia con lo ya establecido por la IV Conferencia Mundial sobre las Mujeres, celebrada en Pekín, en septiembre de 1995, donde se consideraba como objetivo estratégico fomentar una armonización de responsabilidades laborales y familiares entre hombres y mujeres. Así, la ley introduce cambios legislativos en el ámbito laboral para que los trabajadores puedan participar de la vida familiar, dando un nuevo paso en el camino de la igualdad de oportunidades entre mujeres y varones. Trata, además, de guardar 
un equilibrio para favorecer los permisos por maternidad y paternidad sin que ello afecte negativamente a las posibilidades de acceso al empleo, a las condiciones del trabajo y al acceso a puestos de especial responsabilidad de las mujeres.

En relación con la corresponsabilidad de varones y mujeres en las responsabilidades familiares destacan dos modificaciones significativas. Por un lado, se facilita a los varones la coparticipación en el cuidado de sus hijos desde el mismo momento del nacimiento o de su incorporación a la familia. Para lo cual se introduce una modificación que permite conceder a la mujer la opción de que sea el padre el que disfrute hasta un máximo de diez semanas de las dieciséis correspondientes al permiso por maternidad, permitiendo además que lo disfrute simultáneamente con la madre, y se amplía el permiso de maternidad en dos semanas más por cada hijo en el caso de parto múltiple. Asimismo, se introducen importantes modificaciones en la regulación de los permisos por adopción y acogimiento permanente y preadoptivo. Por otro lado, se amplían los permisos para la reducción de la jornada por motivos familiares ${ }^{19}$, y el derecho a la reducción de jornada y excedencia de los trabajadores que tengan que ocuparse de personas mayores y enfermas ${ }^{20}$; según la exposición de motivos, esto último se encuentra "en línea con los cambios demográficos y el envejecimiento de la población".

Como novedad se amplían los supuestos en que no pueden computarse como faltas de asistencia a efectos de extinción del contrato de trabajo por

19 Artículo segundo de la Ley $N^{\circ} 39 / 1999$. Reducción de la jornada laboral por motivos familiares. El apartado 4 del artículo 37 de la Ley del Estatuto de los Trabajadores, aprobado por el Real Decreto Legislativo $N^{\circ} 1 / 1995$, queda redactado de la siguiente forma: "Las trabajadoras, por lactancia de un hijo menor de nueve meses, tendrán derecho a una hora de ausencia del trabajo, que podrán dividir en dos fracciones. La mujer, por su voluntad, podrá sustituir este derecho por una reducción de su jornada en media hora con la misma finalidad. Este permiso podrá ser disfrutado indistintamente por la madre o el padre en caso de que ambos trabajen".

20 Artículo cuarto de la Ley $N^{o} 39 / 1999$. Excedencia por cuidado de familiares. El apartado 3 del artículo $6^{\circ}$, Ley del Estatuto de los Trabajadores, aprobado por el Real Decreto Legislativo $\mathrm{N}^{\circ}$ 1/1995, de 24 de marzo, queda redactado de la forma siguiente: "Los trabajadores tendrán derecho a un período de excedencia de duración no superior a tres años para atender al cuidado de cada hijo, tanto cuando lo sea por naturaleza, como por adopción, o en los supuestos de acogimiento, tanto permanente como preadoptivo, a contar desde la fecha de nacimiento 0 , en su caso, de la resolución judicial o administrativa. También tendrán derecho a un período de excedencia, de duración no superior a un año, salvo que se establezca una duración mayor por negociación colectiva, los trabajadores para atender al cuidado de un familiar, hasta el segundo grado de consanguinidad o afinidad, que por razones de edad, accidente o enfermedad no pueda valerse por sí mismo, y no desempeñe actividad retribuida. La excedencia contemplada en el presente apartado constituye un derecho individual de los trabajadores, hombres o mujeres". 
absentismo laboral. Entre ellos se incluyen el riesgo durante el embarazo, las enfermedades causadas por el mismo, el parto y la lactancia. Por otra parte, prevé las modificaciones que han de realizarse en el Estatuto de los Trabajadores, relativas a la extinción del contrato de trabajo. Para ello, se declara expresamente nula la decisión extintiva o el despido motivado, entre otros, por el embarazo, la solicitud o disfrute de los permisos por maternidad, paternidad o cuidado de familiares, o el despido de los trabajadores con contrato de trabajo suspendido, salvo que se demuestre su procedencia por causa ajena a la discriminación.

Otra de las novedades importante es la creación de una nueva prestación dentro de la acción protectora de la seguridad social, donde incluye la causa de riesgo durante el embarazo, para proteger la salud de la mujer trabajadora embarazada ${ }^{21}$. Esta medida, además de promover el fomento del empleo, tiene la finalidad de que los costes sociales de estos permisos no recaigan sobre los empresarios, y evitar así las consecuencias negativas que derivan de esta situación para el acceso al empleo, especialmente de la población femenina. En el mismo sentido, prevé reducciones en las cotizaciones empresariales a la seguridad social por contingencias comunes, siempre que se contrate interinamente a desempleados para sustituir al trabajador o trabajadora durante los períodos de descanso por maternidad, adopción o acogimiento.

Por último, se destaca el esfuerzo de los legisladores por enfatizar la protección de la maternidad. En lo que respecta a la regulación de los riesgos laborales, se introducen modificaciones para la evaluación de los riesgos a los que se refiere el artículo 16 de la Ley $N^{o} 31 / 1995$, precisamente reguladora de esta especialidad. Por tanto, se incorpora la obligatoriedad de considerar la exposición de las trabajadoras en situación de embarazo o parto reciente, a fin de que sus tareas de trabajo no puedan influir negativamente en la salud de las trabajadoras o del feto. En caso de que los resultados de la evaluación revelasen un riesgo para la seguridad y la salud o una posible repercusión sobre el embarazo o la lactancia de las citadas trabajadoras, el empresario deberá adoptar las medidas necesarias para evitar la exposición a dicho riesgo, a través de una adaptación de las condiciones o del tiempo de trabajo de la trabajadora afectada, o bien, cuando resulte necesario, la no realización de trabajo nocturno o de trabajo a turnos. En caso de imposibi-

21 Artículo duodécimo de la Ley $N^{\circ} 39 / 1999$. Duración de la obligación de cotizar. Se modifica el apartado 4 del artículo 106 de la Ley General de la Seguridad Social, que queda redactado en los siguientes términos: "La obligación de cotizar continuará en las situaciones de incapacidad temporal, cualquiera que sea su causa, en la de riesgo durante el embarazo y en la de maternidad, así como en las demás situaciones previstas en el artículo 125 en que así se establezca reglamentariamente". 
lidad, podrá declararse el paso de la trabajadora afectada a la situación de suspensión del contrato por riesgo durante el embarazo. Además, durante el período prenatal la mujer embarazada tendrá derechos para ausentarse ocasionalmente del lugar de trabajo en caso de ser necesario, previo aviso y justificación ${ }^{22}$.

\section{III.b. Segunda etapa: Ley $N^{o} 3 / 2007$, de 22 de marzo, para la igualdad de oportunidades entre mujeres $y$ hombres}

Luego, en el año 2007, España introduce nuevas ampliaciones y modificaciones a partir de la Ley $N^{o} 3 / 2007$ para la igualdad de oportunidades entre mujeres y hombres. Esta normativa tiene un mayor alcance que la anterior. Se refiere a la generalidad de las políticas públicas en España, tanto estatales, como autonómicas y locales. Marca un camino en la prevención de conductas discriminatorias por razones de sexo y en la previsión de políticas públicas y privadas activas para hacer efectivo el principio de igualdad. "La ley nace con la vocación de erigirse en la ley-código de la igualdad entre mujeres y hombres" (p. 8). Constituye la ordenación general para las políticas públicas.

Con esta normativa se incorporan medidas para garantizar la igualdad entre mujeres y hombres en el acceso al empleo, en la formación y en la promoción profesionales, y en las condiciones de trabajo ${ }^{23}$. Se incluye, además, entre los derechos laborales de los trabajadores y las trabajadoras, la protección frente al acoso sexual y al acoso por razón de sexo. Asimismo, se determinan las consecuencias jurídicas de las conductas discriminato-

22 Las trabajadoras embarazadas tendrán derecho a ausentarse del trabajo, con derecho a remuneración, para la realización de exámenes prenatales y técnicas de preparación al parto, previo aviso al empresario y justificación de la necesidad de su realización dentro de la jornada de trabajo.

23 Artículo 42 de la Ley $N^{o} 3 / 2017$. "Programas de mejora de la empleabilidad de las mujeres. 1) Las políticas de empleo tendrán como uno de sus objetivos prioritarios aumentar la participación de las mujeres en el mercado de trabajo y avanzar en la igualdad efectiva entre mujeres y hombres. Para ello, se mejorará la empleabilidad y la permanencia en el empleo de las mujeres, potenciando su nivel formativo y su adaptabilidad a los requerimientos del mercado de trabajo. 2) Los Programas de inserción laboral activa comprenderán todos los niveles educativos y edad de las mujeres, incluyendo los de Formación Profesional, Escuelas Taller y Casas de Oficios, dirigidos a personas en desempleo, se podrán destinar prioritariamente a colectivos específicos de mujeres o contemplar una determinada proporción de mujeres". 
rias e incorpora garantías de carácter procesal para reforzar la protección judicial del derecho de igualdad. Además, insiste en el deber general de las empresas de respetar el principio de igualdad en el ámbito laboral, a partir de la obligación de negociar planes de igualdad en las empresas de más de doscientos cincuenta trabajadores o trabajadoras; y sugiere también la previsión del fomento de su implantación voluntaria en las pequeñas y medianas empresas.

Con relación específicamente a los derechos de conciliación de la vida personal, familiar y laboral, con el fin de contribuir a un reparto más equilibrado de las responsabilidades familiares, tiene como principal medida el reconocimiento a los padres del derecho a un permiso y una prestación por paternidad, en los términos previstos en la normativa laboral y de seguridad social ${ }^{24}$. Esto significa un derecho individual y exclusivo del padre, que se reconoce tanto en los supuestos de paternidad biológica como en los de adopción y acogimiento, que implica trece días de permiso por paternidad, ampliable en caso de nacimiento múltiple en dos días más por cada hijo a partir del segundo. Posteriormente, la legislación avanzará en este sentido y va a introducir nuevas modificaciones con el objetivo de equiparar la duración del permiso por paternidad al de maternidad.

También se introducen mejoras en el permiso de maternidad, vigente en ese momento, ampliándolo en dos semanas para los supuestos de hijo con discapacidad, pudiendo hacer uso de esta ampliación indistintamente ambos progenitores. Estas mismas mejoras se extienden igualmente a los trabajadores y trabajadoras autónomos y de otros regímenes especiales de la seguridad social. En relación con la reducción de jornada por guarda legal, por un lado, se amplía la edad máxima del menor que da derecho a la reducción, pasa de seis a ocho años; y, por otro lado, se reduce por otra, a un octavo de la jornada el límite mínimo de dicha reducción. Se reduce a cuatro meses la duración mínima de la excedencia voluntaria y se amplía de uno a dos años la duración máxima de la excedencia para el cuidado de familiares. Se reconoce la posibilidad de que tanto la excedencia por cuidado de hijo como la de por cuidado de familiares puedan disfrutarse de forma fraccionada.

24 Artículo 133 de la Ley $N^{\circ}$ 3/2007. "Paternidad. Situación protegida: A efectos de la prestación por paternidad, se considerarán situaciones protegidas el nacimiento de hijo, la adopción y el acogimiento, tanto preadoptivo como permanente o simple, de conformidad con el Código Civil o las leyes civiles de las Comunidades Autónomas que lo regulen, siempre que, en este último caso, su duración no sea inferior a un año [...]". 


\section{III.c. Tercera etapa: Real Decreto Ley $N^{o}$ 6/2019, de 11 de marzo, de medidas urgentes para garantía de la igualdad de trato y de oportunidades entre mujeres y hombres en el empleo y la ocupación}

A partir de las nuevas directivas de la Unión Europea del año 2019 (Directiva 2019/1158), se dicta en España el Real Decreto Ley $N^{\circ} 6 / 2019$, de $1^{\circ}$ de marzo, de medidas urgentes para garantía de la igualdad de trato y de oportunidades entre mujeres y hombres en el empleo y la ocupación. Por él, se declaran expresamente contrarios a este derecho todas las discriminaciones directas e indirectas; el acoso sexual y el acoso por razón de sexo; la discriminación por el embarazo, la maternidad, la asunción de obligaciones familiares o el ejercicio de los derechos de corresponsabilidad de la vida personal, familiar y laboral; las represalias como consecuencia de las denuncias contra actos discriminatorios; y los actos y cláusulas de los negocios jurídicos que constituyan o causen discriminación por razón de sexo. De esta forma, se implementan las nuevas directrices que deberán ser puestas en valor por diferentes leyes vigentes, entre las que se encuentran las relacionadas con la conciliación de la vida personal, familiar y laboral.

Lo que busca esta nueva ley es dar un paso importante en la consecución de la igualdad real y efectiva entre hombres y mujeres, a través de dos elementos esenciales: 1) la promoción de la conciliación de la vida personal y familiar y 2) el principio de corresponsabilidad entre ambos progenitores. De momento, al ser reciente su aprobación no podemos arribar a ningún resultado en función de su incidencia real. Pero sí vale la pena destacar las principales modificaciones que significan un nuevo intento, el tercero, en el diseño formal de políticas públicas.

En esta ocasión, la ley remarca el derecho de los trabajadores a la conciliación de la vida personal, familiar y laboral; el derecho del trabajador a la remuneración correspondiente a su trabajo en el marco de una igualdad de remuneración sin discriminación de $\mathrm{sexo}^{25}$. Se crea una nueva presta-

25 Artículo $2^{\circ}$. Modificación del texto refundido de la Ley del Estatuto de los Trabajadores, aprobado por Real Decreto Legislativo $N^{o} 2 / 2015$, de 23 de octubre. Siete. Se modifica el artículo 28, con la siguiente redacción: "Igualdad de remuneración por razón de sexo. 1. El empresario está obligado a pagar por la prestación de un trabajo de igual valor la misma retribución, satisfecha directa o indirectamente, y cualquiera que sea la naturaleza de la misma, salarial o extrasalarial, sin que pueda producirse discriminación alguna por razón de sexo en ninguno de los elementos o condiciones de aquella. Un trabajo tendrá igual valor que otro cuando la naturaleza de las funciones o tareas efectivamente encomendadas, las condiciones 
ción para el ejercicio corresponsable del cuidado del lactante, conforme a las novedades introducidas tanto en el Estatuto de los Trabajadores como en el Estatuto Básico del Empleado Público. Se pone en valor la figura del cuidador no profesional de personas en situación de dependencia, que en diversas ocasiones se ve obligado a abandonar su puesto de trabajo, y, por tanto, a interrumpir su carrera de cotización a la seguridad social por esta razón.

Un párrafo aparte merece la equiparación, en sus respectivos ámbitos de aplicación, de la duración de los permisos por nacimiento de hijo de ambos progenitores. Este permiso comprende el parto y el cuidado de los menores de doce meses, e implica la suspensión del contrato de trabajo de la madre biológica y el progenitor durante dieciséis semanas, de las cuales serán obligatorias las seis semanas ininterrumpidas inmediatamente posteriores al parto, que habrán de disfrutarse a jornada completa, para asegurar la protección de la salud de la madre y el cumplimiento de los deberes de cuidado previstos en el artículo 68 del Código Civil. Una vez transcurridas las primeras seis semanas, podrá distribuirse a voluntad de aquellos, en períodos semanales a disfrutar de forma acumulada o interrumpida, y ejercitarse desde la finalización de la suspensión obligatoria posterior al parto hasta que el menor cumpla doce meses. No obstante, la madre biológica podrá anticipar su ejercicio hasta cuatro semanas antes de la fecha previsible del parto.

Este derecho es individual de la persona trabajadora, sin que pueda transferirse su ejercicio al otro progenitor, y constituye toda una apuesta en materia de licencias de maternidad y paternidad, ya que pretende quitar el sesgo del sexo a los efectos laborales que derivan del nacimiento de un hijo en aras al cumplimiento del principio de corresponsabilidad. Quedan muchas dudas acerca de cómo funcionará esta medida, cómo la acatarán los trabajadores y cómo responderá el ambiente laboral frente a este nuevo modo de administrar los tiempos entre el trabajo y la familia sugerido por la misma norma estatal; y principalmente cabe esperar qué consecuencias tendrá en la vida personal y familiar de varones y mujeres a la hora de integrar sus responsabilidades laborales.

educativas, profesionales o de formación exigidas para su ejercicio, los factores estrictamente relacionados con su desempeño y las condiciones laborales en las que dichas actividades se llevan a cabo en realidad sean equivalentes". 


\section{Las políticas legislativas de conciliación del trabajo y la vida personal y familiar en Argentina. Marco jurídico de los aspectos claves de la conciliación}

La familia tiene una función social esencial, que es el cuidado y la educación de las vidas que genera, y constituye el espacio donde se proporciona de modo insustituible y eficaz la atención a cada miembro con un cúmulo de tareas que requieren ciertos elementos esenciales, como el tiempo, el cariño y la cercanía ${ }^{26}$. El impacto que produce tanto en la educación como en el cuidado de los hijos la falta de mejores condiciones para que varones y mujeres puedan establecer estrategias de conciliación, o bien las dificultades que se presentan para decidir tener hijos, trabajar y cuidar a los más vulnerables del grupo familiar, exige una visión legislativa más amplia que la que ofrece la legislación laboral. Por eso, a continuación, se observan los principios constitucionales, los tratados internacionales suscriptos por Argentina y a los que les ha otorgado jerarquía constitucional, con relación al cuidado y la igual protección ante la ley de los niños y niñas, sin dejar de considerar la legislación vigente en materia de trabajo. De esta manera, se evidencia un marco jurídico amplio y propicio para el diseño de políticas públicas de conciliación basada en la corresponsabilidad y solidaridad familiar.

El principio contemplado en el artículo 14 bis de la Carta Magna de Argentina establece, en un sentido general, "la protección integral de la familia”, y que debe ser armonizado con el derecho de todo ciudadano a trabajar del artículo 14, de tal manera que se favorezca el equilibrio y la tranquilidad familiar. Los progenitores, al ejercer su deber de cuidado y protección de los más vulnerables en el ámbito familiar, dan real significancia al interés superior del niño y es el Estado quien debe orientar las políticas públicas en tal sentido. En la Constitución Nacional, el inciso 23 del artículo 75 contiene un mandato claro del constituyente que no puede ser soslayado ni contradicho por las normas inferiores: "Legislar y promover medidas de acción positiva que garanticen la igualdad real de oportunidades y de trato, y el pleno goce y ejercicio de los derechos reconocidos por esta Constitución y por los Tratados Internacionales sobre Derechos Humanos vigentes, en particular respecto de los niños, las mujeres, los ancianos y las personas con discapacidad. Dictar un régimen de seguridad social especial e integral en protección del niño en situación de desamparo, desde el embarazo hasta la

26 Gas Aixendri, M. (2015). "La familia: clave para la humanización de la sociedad". En Debeljuh, P. y Destéfano, A. Hacia un nuevo pacto entre trabajo y familia: Guía de buenas prácticas. Ciudad Autónoma de Buenos Aires. Baur, 62. 
finalización del período de enseñanza elemental, y de la madre durante el embarazo y el tiempo de lactancia".

El Preámbulo de la Convención sobre los Derechos del Niño reconoce "que el niño, para el pleno y armonioso desarrollo de su personalidad, debe crecer en el seno de la familia, en un ambiente de felicidad, amor y comprensión", y que debe tenerse muy en cuenta "que, como se indica en la Declaración de los Derechos del Niño, el niño, por su falta de madurez física y mental, necesita protección y cuidado especiales, incluso la debida protección legal, tanto antes como después del nacimiento; [...]". Similares conceptos sobre el cuidado y la igual protección ante la ley de los niños y niñas se sustentan en la Declaración Universal de los Derechos Humanos: "[...] la maternidad y la infancia tienen derecho a cuidados y asistencias especiales. Todos los niños [...] tienen derecho a igual protección social" (art. 25.2); en el Pacto Internacional de Derechos Civiles y Políticos: "[...] todo niño tiene derecho, sin discriminación alguna [...] a las medidas de protección que su condición de menor [...]" (art. 24.1); en el Pacto Internacional de Derechos Económicos, Sociales y Culturales: "[...] se deben adoptar medidas especiales de protección y asistencia en favor de todos los niños y adolescentes, sin discriminación alguna" (art. 10.3); en la Declaración Americana de Derechos y Deberes del Hombre: "[...] todo niño, tiene derecho a protección, cuidados y ayudas especiales" (art. VII) y en la Convención Americana sobre Derechos Humanos: "[...] todo niño tiene derecho a las medidas de protección que su condición de menor requieren por parte de su familia, de la sociedad y del Estado" (art. 19). Estos Tratados de Derechos Humanos han sido incorporados al bloque de constitucionalidad reforzada agregado por la última reforma a la Constitución Nacional en su artículo 75, inciso 22.

Las nuevas fisonomías familiares obligan a repensar la asignación de responsabilidades y funciones dentro de la organización familiar, producto, muchas veces, de la necesidad de generar los medios necesarios para su subsistencia. En tal sentido, la plenitud del amor de los progenitores y la felicidad del niño se ven apremiadas por las circunstancias económicas, no pocas veces estimuladas por un contexto utilitarista y mezquino. Sin embargo, pensar en el bienestar del niño no es sólo contemplar sus requerimientos materiales, sino también afectivos y emocionales básicos, como se reconocen en la mencionada Convención sobre la niñez, en sus artículos $3^{\circ}, 9^{\circ}$ y 12 , que tiene como principio inspirador "el interés superior del niño". Su artículo 18 contempla claramente que: "1. Los Estados Parte pondrán el máximo empeño en garantizar el reconocimiento del principio de que ambos padres tienen obligaciones comunes en lo que respecta a la crianza y el desarrollo del niño. Incumbirá a los padres o, en su caso, a los representantes legales la responsabilidad primordial de la crianza y el desarrollo del niño. Su preocupación fundamental será el interés superior del niño". 
Por su parte, la Convención sobre la Eliminación de todas las Formas de Discriminación contra la Mujer (CEDAW), también incorporada al texto constitucional argentino, en su artículo 16 establece: "Los Estados Partes adoptarán todas las medidas adecuadas para eliminar la discriminación contra la mujer en todos los asuntos relacionados con el matrimonio y las relaciones familiares y, en particular, asegurarán, en condiciones de igualdad entre hombres y mujeres: [...] d) Los mismos derechos y responsabilidades como progenitores, cualquiera que sea su estado civil, en materias relacionadas con sus hijos; en todos los casos, los intereses de los hijos serán la consideración primordial; e) Los mismos derechos a decidir libre y responsablemente el número de sus hijos y el intervalo entre los nacimientos y a tener acceso a la información, la educación y los medios que les permitan ejercer estos derechos [...]". En el mismo sentido, la Ley Nacional No 26.061 de Protección Integral de la Niñez, en su artículo $7^{\circ}$, párrafo $2^{\circ}$, establece: "El padre y la madre tienen responsabilidades y obligaciones comunes e iguales en lo que respecta al cuidado, desarrollo y educación integral de sus hijos". Cabe destacar que las dificultades para conciliar la vida laboral y familiar, tanto de padres como de madres, impactan de lleno sobre la educación, el desarrollo y las necesidades propias de los hijos, variando conforme sea la etapa vital que estén transitando.

En lo que respecta al Código Civil y Comercial de la Nación Argentina, aprobado por Ley $\mathrm{N}^{\circ} 26.994$, debemos decir que en torno a la familia se produjo uno de los cambios más importantes y que la nueva norma asume una visión de preeminencia de la autonomía de la voluntad que desfigura varios rasgos esenciales de la institución familiar. Con todo, en el orden público familiar contemplado en la actual redacción de este Código, en lo que concierne específicamente a la corresponsabilidad de los padres en relación con los hijos, adopta una forma equilibrada que se adecúa a los Tratados Internacionales de Derechos Humanos ${ }^{27}$. En su integralidad ha pretendido asumir la igualdad de los cónyuges con la equiparación de los derechos y deberes matrimoniales y parentales (art. 402). Asimismo, en su artículo 638 define el concepto de responsabilidad parental como "el conjunto de deberes y derechos que corresponden a los progenitores sobre la persona y bienes del hijo, para su protección, desarrollo y formación integral mientras sea menor de edad y no se haya emancipado". Entre los primeros incisos del artículo 646 se enumeran como deberes de los progenitores: "a) cuidar del hijo, convivir con él, prestarle alimentos y educarlo; b) considerar las necesidades específicas del hijo según sus características psicofísicas, aptitudes

27 Cfr. Medina, G. y Roveda, E. (2017). Manual de Derecho de Familia. Buenos Aires. Ed. Abeledo Perrot, 58. 
y desarrollo madurativo; [...]". De esta manera, estos artículos destacan la responsabilidad parental no sólo como una institución que tiene la finalidad protectoria de los hijos, sino que contemplan la función irreemplazable de los padres para su desarrollo y formación integral. Si bien el cambio de nomenclatura introducido en la reforma del año 2015 pretendió evitar la tradicional denominación de "patria potestad", creemos que no altera su contenido histórico sobre la misión natural, compartida e indelegable que tienen los padres respecto de la persona y los intereses del niño ${ }^{28}$.

Este concepto de responsabilidad incorporado a la redacción del Código en vigencia a partir de 2015 está en sintonía con la Ley No 26.061 de Protección Integral de los Derechos de Niñas, Niños y Adolescentes, donde se establece, en su artículo $7^{\circ}$ : "La familia es responsable en forma prioritaria de asegurar a las niñas, niños y adolescentes el disfrute pleno y el efectivo ejercicio de sus derechos y garantías. El padre y la madre tienen responsabilidades y obligaciones comunes e iguales en lo que respecta al cuidado, desarrollo y educación integral de sus hijos. Los Organismos del Estado deben asegurar políticas, programas y asistencia apropiados para que la familia pueda asumir adecuadamente esta responsabilidad, y para que los padres asuman, en igualdad de condiciones, sus responsabilidades y obligaciones". Por tanto, el problema de la conciliación del trabajo y la vida familiar que se presenta en la actualidad a padres y madres debe ser considerado por los legisladores y así realizar las adecuaciones legales pertinentes para crear las condiciones necesarias donde en el seno de la familia se puedan diseñar las estrategias pertinentes conforme lo exijan las circunstancias particulares. Para eso, deben ponderarse las nuevas realidades familiares desde una óptica de responsabilidades compartidas y complementarias en orden a la protección y crianza del hijo. Esta es una premisa que ha de orientar las políticas públicas de asistencia al grupo familiar con criterios de solidaridad.

En el ámbito del Derecho del Trabajo, un aspecto muy importante para tener en cuenta y que tiene una relación estrecha con la conciliación de la vida laboral y familiar es la licencia por maternidad de la Ley de Contrato de Trabajo ( $\mathrm{N}^{\circ}$ 20.744/1976), que está basada en la función reproductiva de la mujer, desconociendo los requerimientos de atención que de ella y del niño se requieren, tanto antes como después del nacimiento ${ }^{29}$. La LCT $\mathrm{N}^{\circ}$

28 Cfr. Perrino, J. O. y Basset, U. C. (2017). Derecho de Familia. $3^{a}$ Edición. Buenos Aires. Abeledo Perrot, 2136.

29 “Artículo 177 .- Prohibición de trabajar. Conservación del Empleo. Queda prohibido el trabajo del personal femenino durante los cuarenta y cinco (45) días anteriores al parto y hasta cuarenta y cinco (45) días después del mismo. Sin embargo, la interesada podrá optar por que se le reduzca la licencia anterior al parto, que en tal caso no podrá ser inferior a treinta (30) días; el resto del período total de licencia se acumulará al período de descanso posterior al 
20.744/1976 ${ }^{30}$ se centra en el estado de gravidez de la mujer, omitiendo los derechos básicos de cuidado del niño, a tal punto que las licencias por paternidad son solo de dos días, con la intención de dar solución a las circunstancias urgentes del nacimiento del niño, descentrándose el cometido de la idea de padre como sujeto corresponsable. Si bien los costos de los 90 días en el caso de la licencia por maternidad son absorbidos por el sistema de seguridad social de la Nación (ANSES), en la legislación argentina existe un tratamiento distinto entre los agentes privados o públicos en este aspecto. Esto genera una diferenciación injusta en la licencia que disponen los trabajadores que depende de la fuente laboral de que se trate ${ }^{31}$.

En la actualidad, existen numerosos y recurrentes proyectos de ley en ambas cámaras del Congreso Nacional con estado parlamentario, que proponen una modificación en el período de maternidad y paternidad, antes y después del nacimiento, como así también con relación a las tareas de cuidado y a los derechos de la seguridad social ${ }^{32}$. Lo cual revela una real necesidad de revisar estos aspectos que tienen una relación directa con un problema que afecta a varones y mujeres y que en las últimas décadas se ha convertido en una cuestión social. Sin embargo, si bien las propuestas tienden mayoritariamente hacia una ampliación de los períodos de licencia,

parto. En caso de nacimiento pretérmino se acumulará al descanso posterior todo el lapso de licencia que no se hubiere gozado antes del parto, de modo de completar los noventa (90) días. La trabajadora deberá comunicar fehacientemente su embarazo al empleador, con presentación de certificado médico en el que conste la fecha presunta del parto, o requerir su comprobación por el empleador. La trabajadora conservará su empleo durante los períodos indicados, y gozará de las asignaciones que le confieren los sistemas de seguridad social, que garantizarán a la misma la percepción de una suma igual a la retribución que corresponda al período de licencia legal, todo de conformidad con las exigencias y demás requisitos que prevean las reglamentaciones respectivas. Garantízase a toda mujer durante la gestación el derecho a la estabilidad en el empleo. El mismo tendrá carácter de derecho adquirido a partir del momento en que la trabajadora practique la notificación a que se refiere el párrafo anterior. En caso de permanecer ausente de su trabajo durante un tiempo mayor, a consecuencia de enfermedad que según certificación médica deba su origen al embarazo o parto y la incapacite para reanudarlo vencidos aquellos plazos, la mujer será acreedora a los beneficios previstos en el artículo 208 de esta ley".

30 Publicada en el Boletín Oficial del 27/9/1974 (BO 23.003). Según texto ordenado del año 1976 y sus modificatorias.

31 Ver Ley No 20.744 (Ley de Contrato de Trabajo), Ley No 26.727 (Régimen de Trabajo Agrario), Decreto No 214/2006 (Convenio Colectivo de Trabajo), Ley No 26.844 (Servicio Doméstico - Régimen Especial de Contrato de Trabajo) y legislaciones provinciales.

32 Algunos de los Proyectos de Ley con estado parlamentario en el Honorable Senado de la Nación Argentina: S-0508/19; S-3006/19; S-1376/2020; S-1937/2020; S-0097/2020; S-0020/2020. En la Honorable Cámara de Diputados de la Nación: 0222-D-2019; 5218-D-2019; 4731-D-2019. Disponibles según $\mathrm{N}^{\circ}$ de expediente y Cámara de origen, en https://www.senado. gob.ar/ y en https://www.hcdn.gob.ar/index.html, fecha de última consulta: 2/10/2020. 
se advierten que las finalidades buscadas por los legisladores son diversas. No es lo mismo poner en el centro al individuo que hacerlo contemplando al núcleo familiar, que es, en definitiva, el entorno donde se gestiona la conciliación y se establecen las estrategias más convenientes.

Ciertamente, en Argentina no existe una legislación concreta que regule la conciliación del trabajo y la vida personal y familiar, como sí se observa en el caso español. Pero sí se evidencia un marco jurídico que regula diferentes aspectos de la conciliación separados en diversos textos normativos. Sin embargo, aún resultan insuficientes para hacer frente a las transformaciones y exigencias sociales donde varones y mujeres consideran en su proyecto vital tanto el trabajo como la familia. Por eso, creemos imprescindible revisar las políticas públicas laborales, sociales y de familia en Argentina, con miradas integradoras tendientes a contemplar las nuevas realidades y los cambios demográficos actuales. Esto implica definir políticas concretas de conciliación, capaces de crear las condiciones necesarias para que varones y mujeres dentro del seno de la familia puedan establecer, en un marco de libertad, las estrategias que consideren de acuerdo con sus circunstancias particulares y en un plano de igualdad de oportunidades.

\section{Retos legislativos en materia de políticas públicas de conciliación en Argentina}

La evolución de las políticas legislativas tendientes a facilitar la armonía de la vida laboral y familiar que se refleja en el análisis de la legislación española pone en evidencia la necesidad del ordenamiento jurídico argentino, de una actualización acorde a las transformaciones sociales que se han suscitado en las últimas décadas. Los cambios en el papel de la mujer en la sociedad, las nuevas exigencias y las expectativas laborales tanto en varones como mujeres exigen un nuevo modo de comprender la relación de la vida laboral y familiar. Es necesario repensar el modo de distribuir las responsabilidades familiares y laborales, conforme su carácter de irrenunciables e indelegables ${ }^{33}$. La corresponsabilidad entre varones y mujeres, sea en la misma pareja o conforme pasen los años en el mismo núcleo familiar, se presenta como la mejor alternativa para cuidar, promover e instaurar una modalidad donde todos los integrantes de la familia puedan desarrollarse plenamente en lo personal, laboral y familiar.

33 Cfr. Méndez Costa, M. J.; Ferrer, F. A. M. y D’Antonio, D. H. (2008). Derecho de Familia. Tomo IV. Santa Fe. Rubinzal Culzoni, 135 y sigs. 
Como se desprende del caso español, la tendencia legislativa en asuntos de conciliación está fuertemente definida hacia una regulación promotora de la corresponsabilidad. Sin dejar de reconocer la importancia de esta adecuación en las políticas públicas, se hace imprescindible salvaguardar la entidad familiar y reconocer que la familia no es isomórfica en el tiempo, sino que pasa por diversas etapas que tienen relación con aquellas que atraviesan sus miembros; hay períodos más complejos y difíciles que otros, hay etapas de adaptación, de mayor estrés, y también de estabilidad ${ }^{34}$. Lo cual exige evitar caer en un modelo de igualitarismo donde la misma letra normativa establezca cómo y de qué manera los miembros de la familia deben distribuir las responsabilidades laborales y familiares.

Desde esta perspectiva, es crucial que las políticas públicas creen las condiciones necesarias para que en un marco de libertad y de igualdad de oportunidades, varones y mujeres en el seno de la familia puedan establecer las estrategias más convenientes según sus circunstancias particulares. De ahí que las políticas tendientes a facilitar las licencias parentales por razones de cuidado y atención a los más vulnerables de la familia, para varones y mujeres en el ámbito laboral, resulten muy favorables y bien recibidas por los trabajadores, no sólo porque facilitan la conciliación, sino porque también repercuten en una mejor paternidad y maternidad y, por ende, impactan positivamente en la educación y en el desarrollo de los hijos.

En el año 2009, la OIT establece una serie de recomendaciones con la finalidad de que la conciliación de la vida laboral y familiar sea una cuestión que contemple a varones y mujeres, dado que estas tensiones significan enormes costos para las personas y para la sociedad en su conjunto, y, por lo tanto, demandan una urgente respuesta por parte de los Estados, en colaboración con los actores sociales ${ }^{35}$. En línea a esto, propone la promoción de modelos alternativos de maternidad y paternidad como requisito para el éxito de las políticas de conciliación. Esto implica dar un nuevo significado al papel de los padres dentro de la familia, como personas afectivas, interesadas y capaces de asumir responsabilidades familiares: crianza de hijos, cuidado de ancianos y familiares enfermos, tareas domésticas ${ }^{36}$.

Estas indicaciones pueden plasmarse, por ejemplo, con una política de licencia de paternidad cuyo espíritu sea asociado al rol y valor del padre en

34 Cfr. Polaino-Lorente, A. (2015). "Actividad profesional y dedicación a la familia”. En Domènec Melé (Ed.). Empresa y vida familiar. IV Coloquio de ética empresarial y económica. Barcelona. Estudios y ediciones IESE, 117-136.

35 OIT-PNUD, ob. cit.

36 Ibídem, 117. 
el cuidado del recién nacido, y no como mero encargado de realizar las diligencias formales pertinentes. Sería recomendable en Argentina un debate sobre la ampliación del período de licencia por paternidad, como así también la posibilidad de que tanto padres y madres puedan disponer de recursos y herramientas que les permitan optar-según las necesidades particularespor atender y cuidar a sus hijos, principalmente en las etapas de mayor dependencia y vulnerabilidad, sin que esto signifique un desmedro en su carrera profesional. Asimismo, evaluar el impacto de la ampliación de los horarios escolares y preescolares, y favorecer mecanismos de flexibilidad horaria en trabajos del ámbito público y privado pueden formar parte del elenco de políticas de conciliación a promover.

Igualmente importante, según la OIT, es, desde la visión del mundo del trabajo, que en lugar de buscar la equidad promoviendo simplemente la incorporación de las mujeres a un mercado laboral, lo que se requiere es redefinir la norma del "trabajador ideal": hombre, productivo y sin responsabilidades familiares ${ }^{37}$. Este cambio de perspectiva se sustenta en la importancia que tiene la maternidad y la paternidad en el desarrollo personal y familiar, como así también para la sociedad. Además, busca ampliar la concepción que se tiene sobre el rol del cuidado y evitar colocar a las mujeres frente al dilema de trabajar o cuidar a los hijos y/o dependientes. Por eso, una política pública orientada únicamente a combatir la penalización por maternidad en el ámbito laboral sin atender al contexto familiar y sus miembros resulta incompleta y puede ser contraria no sólo a la protección de la mujer, sino también provocar una transferencia de estas consecuencias al hecho de tener hijos, tanto a varones como mujeres, dado que el problema en el mercado laboral parece estar relacionado más a una cuestión de productividad que a una cuestión de sexo. Queda claro entonces que ante las nuevas expectativas de la sociedad del siglo XXI las políticas de conciliación son cruciales para que todos los adultos, hombres y mujeres, puedan alcanzar sus ideales familiares y laborales.

Por último, es cierto que las políticas de conciliación del trabajo y la vida personal y familiar en Argentina han tenido una lógica diferente a la que se ha configurado en España, donde el Estado, desde 1999, ha promulgado diferentes normativas en la materia. Según diferentes estudios realizados por el Centro Conciliación Familia y Empresa del IAE, desde principio de siglo son las entidades privadas las que han decidido desarrollar e implementar una serie de medidas propias de cada organización a favor de que los trabajadores puedan integrar sus responsabilidades laborales y familiares ${ }^{38}$.

37 Ibídem, 117.

38 Cfr. Ordoñez y Revuelta, M. E. y Debeljuh, P. (2018). Hacia una responsabilidad com- 
La flexibilidad horaria, la creación de jardines maternales exclusivos de las empresas, la autorización para que en ocasiones el trabajador o trabajadora pueda teletrabajar, e inclusive la ampliación de las licencias por maternidad y paternidad más allá de lo estipulado por la ley. Esto pone en evidencia la necesidad de conciliar, pero exige reconocer que sin una regulación legal que favorezca y cree las condiciones necesarias para el empleador y los trabajadores este tipo de medidas tienen una naturaleza de beneficio y no de derecho ${ }^{39}$; con lo cual, gran parte de la población queda excluida de esta posibilidad.

\section{Conclusiones}

La evolución de las políticas legislativas tendientes a facilitar la armonía de la vida laboral y familiar en España resumidas en este artículo y las transformaciones sociales de las últimas décadas ponen en evidencia la necesidad de actualizar el ordenamiento jurídico argentino. Se impone la necesidad de revisar la normativa vigente desde una perspectiva de solidaridad familiar, superando la mirada individualista que impregna gran parte de su legislación. Para eso, resulta imprescindible contemplar los principios constitucionales de igualdad de oportunidades y libertad de decisión en sintonía con la protección de la institución familiar, a fin de encontrar las condiciones necesarias que alienten el emprendimiento de un proyecto de vida en común basado en la corresponsabilidad y en la vinculación de los demás miembros de la familia. Creemos que un abordaje con mirada sistémica e integral de familia se nos presenta como superador de aquellas iniciativas que solamente contemplan aspectos centrados en el individuo. Procurar una familia estable y duradera, basada en el principio de solidaridad y corresponsabilidad familiar, y teniendo como propósito fundamental la atención de sus miembros más vulnerables, tendrá -seguramente- como correlato una sociedad más saludable y preparada para los desafíos del siglo XXI, como son el cuidado de los dependientes y la armonía e integración de la vida laboral, personal y familiar.

\footnotetext{
partida: Familia, Empresa y Sociedad. Guía de buenas prácticas. Ciudad Autónoma de Buenos Aires. Baur.

39 Cfr. Schenone Sienra, D. y Oliva, M. (2017). La responsabilidad familiar corporativa frente al problema de la conciliación familia-trabajo. Tensiones entre el derecho al cuidado y la inversión en capital humano en la Argentina. Cuadernos de Economía Crítica, Nro. 7, 71-95.
} 


\section{Bibliografía}

CEPAL (2020). Observatorio Demográfico, 2019 (LC/PUB.2019/24-P). Santiago de Chile. Recuperado de https://repositorio.cepal.org/bitstream/handle/11362/45198/1/S1900739_mu.pdf.

Chinchilla, N. y Moragas, M. (2007). Dueños de nuestro destino. Cómo conciliar la vida profesional, familiar y personal. Barcelona. Ariel.

Esping-Andersen, G. y Palier, B. (2010). Los tres grandes retos del Estado del bienestar. Barcelona. Editorial Ariel.

Gas Aixendri, M. (2015). "La familia: clave para la humanización de la sociedad". En Debeljuh, P. y Destéfano, A. Hacia un nuevo pacto entre trabajo y familia: Guía de buenas prácticas. Ciudad Autónoma de Buenos Aires. Baur, 62 .

Goldin, C. (2006). "The Quiet Revolution That Transformed Women's Employment, Education, and Family". En AEA Papers and Proceedings, 1-21.

Hervada, J. (2000). Una caro. Escritos sobre el matrimonio. Pamplona. EUNSA.

INE (2019a). Nota de prensa: Encuesta de Fecundidad 2018. Datos definitivos. Madrid. Recuperado de https://www.ine.es/prensa/ef_2018_a.pdf.

INE (2019b). España en cifras 2019. Madrid. Recuperado de https://www.ine.es/prodyser/espa_cifras/2019/index.html.

Livi Bacci, M. (2012). Historia mínima de la población mundial. $4^{\mathrm{a}}$ ed. Barcelona. Editorial Ariel.

López, D. (2016). "El reto de la conciliación trabajo y familia: ¿qué nos estamos jugando?" En Familia y sociedad en el siglo XXI. Madrid. Dykinson.

Medina, G. y Roveda, E. (2017). Manual de Derecho de Familia. Buenos Aires. Ed. Abeledo Perrot.

Meil Landwerlin, G. (2017). "Permisos parentales para hombres y corresponsabilidad en el cuidado de niños". Revista del Ministerio de Empleo y Seguridad Social, 131, 15-34.

Méndez Costa, M. J.; Ferrer, F. A. M.; D’Antonio, D. H. (2008). Derecho de Familia. Tomo IV. Santa Fe. Rubinzal Culzoni.

OIT-PNUD (2009). Trabajo y Familia: Hacia nuevas formas de conciliación con corresponsabilidad social. Santiago de Chile. Recuperado de http://www.undp.org. $\mathrm{mx} / \mathrm{IMG} / \mathrm{pdf} /$ Trabajoyfamiliainm.pdf.

Olmo Vicén, N.; Montoro Gurich, C. y López, D. (2011). "El reto de tener hijos y trabajar: Un análisis desde la socio-demografía”. En C. Montoro Gurich (Ed.). Familias con dos sueldos y tres trabajos. Pamplona. Instituto de Ciencias para la Familia, Servicio de Publicaciones de la Universidad de Navarra, 86-113.

Ordoñez y Revuelta, M. (2016). Familia + Trabajo: Un camino hacia la integración. Buenos Aires. Lid Editorial.

Ordoñez y Revuelta, M. E. y Debeljuh, P. (2018). Hacia una responsabilidad compartida: Familia, Empresa y Sociedad. Guía de buenas prácticas. Ciudad Autónoma de Buenos Aires. Baur. 
Perrino, J. O. y Basset, U. C. (2017). Derecho de Familia. $3^{\text {a }}$ Edición. Buenos Aires. Abeledo Perrot.

Polaino-Lorente, A. (2015). "Actividad profesional y dedicación a la familia". En Domènec Melé (Ed.). Empresa y vida familiar. IV Coloquio de ética empresarial y económica. Barcelona. Estudios y ediciones IESE, 117-136.

Sánchez Barricarte, J. (2008). El crecimiento de la población mundial. Implicaciones socioeconómicas, ecológicas y éticas. Valencia. Tirant Lo Blanch.

Schenone Sienra, D. y Oliva, M. (2017). La responsabilidad familiar corporativa frente al problema de la conciliación familia-trabajo. Tensiones entre el derecho al cuidado y la inversión en capital humano en la Argentina. Cuadernos de Economía Crítica, Nro. 7, 71-95.

Van De Kaa, D. J. (1997). "Options and sequences: Europe's demographic patterns". Journal of the Australian Population Association, 14 (1), 1-30. 